\title{
Progressive Neuronal and Motor Dysfunction in Mice Overexpressing the Serine Protease Inhibitor Protease Nexin-1 in Postmitotic Neurons
}

\author{
Marita Meins, ${ }^{1}$ Petra Piosik, ${ }^{1}$ Nicole Schaeren-Wiemers, ${ }^{1}$ Stefania Franzoni, ${ }^{1}$ Edgardo Troncoso, ${ }^{2}$ \\ Jozsef Z. Kiss, ${ }^{2}$ Christian Brösamle, ${ }^{3}$ Martin E. Schwab,, ${ }^{3}$ Zoltán Molnár, ${ }^{4}$ and Denis Monard ${ }^{1}$ \\ ${ }^{1}$ Friedrich Miescher-Institut, CH-4058 Basel, Switzerland, 2University of Geneva Medical School, Department of \\ Morphology, CH-1211 Geneva, Switzerland, ${ }^{3}$ Brain Research Institute, University of Zürich and Eidgenössische \\ Technische Hochschule Zürich, CH-8057 Zürich, Switzerland, and 4/nstitute of Cellular Biology and Morphology, CH-1005 \\ Lausanne, Switzerland
}

\begin{abstract}
Perturbation of the homeostasis between proteases and their inhibitors has been associated with lesion-induced or degenerative neuronal changes. Protease nexin-1 ( $\mathrm{PN}-1)$, a secreted serine protease inhibitor, is constitutively expressed in distinct neuronal cell populations of the adult CNS. In an earlier study we showed that transgenic mice with ectopic or increased expression of $\mathrm{PN}-1$ in postnatal neurons have altered synaptic transmission. Here these mice are used to examine the impact of an extracellular proteolytic imbalance on long-term neuronal function. These mice develop disturbances in motor behavior from 12 weeks on, with some of the histopathological changes described in early stages of human motor neuron disease, and
\end{abstract}

neurogenic muscle atrophy in old age. In addition, sensorimotor integration, measured by epicranial multichannel recording of sensory evoked potentials, is impaired. Our results suggest that axonal dysfunction rather than cell death underlies these phenotypes. In particular, long projecting neurons, namely cortical layer $\mathrm{V}$ pyramidal and spinal motor neurons, show an agedependent vulnerability to $\mathrm{PN}-1$ overexpression. These mice can serve to study early stages of in vivo neuronal dysfunction not yet associated with cell loss.

Key words: PN-1; motor behavior; motor neuron disease; proteolytic inhibition; transgenic mice; layer $V$ pyramidal cells; muscle atrophy; axonopathy
Rapid and irreversible cellular responses to developmental and pathological cues can be mediated by the degradation of extracellular matrix proteins or cell surface proteins, as well as by the activation of specific membrane receptors by proteolysis (Monard, 1993; Werb, 1997). Extracellular serine proteases, together with their cognate inhibitors, play an important role in both the developing and adult nervous systems. A disturbed balance between proteolytic activity and protease inhibition in the pericellular environment may contribute to the development of pathological changes during neurodegenerative diseases such as Alzheimer's disease (Wagner et al., 1989; Sisodia et al., 1990; Golde et al., 1992, Vaughan et al., 1994) and amyotrophic lateral

Received June 19, 2001; revised Aug. 20, 2001; accepted Sept. 4, 2001.

This work was funded by the Novartis Research Foundation. We also thank Elisabeth Fries and Sabrina Taieb for valuable technical assistance, Pico Caroni, Corinna Schneider, and Will Spooren for technical advice, Yves-Alain Barde, Patrick King, Andrew Matus, Ulrich Müller, and Kerry Tucker for critical reading of this manuscript, as well as Hans Rudolf Brenner and Alphonse Probst for helpf ul discussions. We are grateful to Pico Caroni for the rat GAP-43 cDNA, Louis Reichardt for the anti-p $75^{\text {NTR }}$ antibody, and the Developmental Studies Hybridoma Bank (Iowa City, IA) for the $2 \mathrm{H} 3$ neurofilament and anti-Islet- 1 antibodies. Pico Caroni and Thorsten Laux generously provided breeding GAP-43 mice.

M.M. and P.P. contributed equally to this work.

Correspondence should be addressed to Dr. Denis Monard, Friedrich MiescherInstitut, Maulbeerstrasse 66, CH-4058 Basel, Switzerland. E-mail: monard@fmi.ch.

Dr. Piosik's present address: F. Hoffmann-La Roche Ltd., CH-4070 Basel, Switzerland.

Dr. Schaeren-Wiemers' present address: Department of Research, Neurobiology, University Hospital Basel, CH-4031 Basel, Switzerland.

Dr. Brösamle's present address: Carnegie Institution, Department of Embryology, Baltimore, MD 21210.

Dr. Molnár's present address: Department of Human Anatomy and Genetics, University of Oxford, Oxford OX1 3QX, UK.

Copyright (C) 2001 Society for Neuroscience $\quad 0270-6474 / 01 / 218830-12 \$ 15.00 / 0$ sclerosis (Chou et al., 1998), the most common form of motor neuron disease.

Protease nexin-1 (PN-1) is a secreted $43 \mathrm{kDa}$ protein of the serpin superfamily (Sommer et al., 1987). It binds and potently inhibits several serine proteases, including thrombin, trypsin, tissue plasminogen activator, urokinase, and Factor XIa (Baker et al., 1980; Monard, 1993; Knauer et al., 2000). It is expressed in distinct temporal and spatial patterns during organogenesis and nervous system development (Mansuy et al., 1993). In the adult CNS, PN-1 is constitutively expressed in several specific neuronal populations, including layer $\mathrm{V}$ pyramidal neurons of the cerebral cortex (Mansuy et al., 1993; Reinhard et al., 1994), whereas PN-1 protein but not its mRNA is found in spinal motor neurons (Niclou et al., 1998). One suggested role of PN-1 in vivo is to circumscribe excessive proteolytic activity in the CNS and PNS after nerve lesion (for review, see Monard et al., 1992; Scotti et al., 1994). In cell culture, $\mathrm{PN}-1$ has been shown to promote neurite outgrowth by preventing the cleavage-induced activation of the thrombin receptor (Suidan et al., 1992) and, together with thrombin, to regulate survival or death of injured neurons (Houenou et al., 1995; Smith-Swintosky et al., 1995; Vaughan et al., 1995; Donovan et al., 1997).

Few studies have examined the role of proteolytic homeostasis in vivo. We have investigated therefore whether perturbing this balance of proteases and their inhibitors by ectopic or increased neuronal PN-1 expression leads to or affects the course of neurodegenerative processes. Young transgenic mice, overexpressing PN-1 postnatally in CNS neurons, showed epileptiform activity and altered hippocampal synaptic transmission and plasticity (Lüthi et al., 1997). Here, we report that these mice develop a 
progressive neurological disorder, featuring motor dysfunction, impaired sensorimotor integration, and a shortened life span. The neuropathological findings include neurogenic muscle atrophy, axonopathy, astrogliosis and microglia activation in the spinal cord and the brain, and neurofilament accumulation in cortical layer V pyramidal cells. These deficits are not associated with a loss of spinal motor or pyramidal neurons in the motor/somatosensory cortex. Our results indicate that overproduction of an endogenous protease inhibitor leads to neurodegenerative processes resulting in functional deficits also found in some types of human motor neuron disease.

\section{MATERIALS AND METHODS}

Analysis of PN-1 transgenic mice. PN-1 transgenic mouse lines (Lüthi et al., 1997) were maintained by backcrossing into either the original C57BL/6 or a BALB/c background. No differences were detected between transgenic TG27 animals backcrossed into either line. Female (f) and male $(\mathrm{m})$ hemizygous transgenic (TG) mice paired with wild-type control (WT) littermates were used. Genotyping was performed on DNA from tail biopsies by PCR. Immunoblot analysis, in situ hybridization (rat GAP-43 cDNA courtesy of Dr. P. Caroni, Friedrich Miescher-Institut, Basel, Switzerland), and protease inhibition assays were performed as described previously (Mansuy et al., 1993; Lüthi et al., 1997; Niclou et al., 1998).

Behavioral analysis. TG and WT littermates (backcrossed for two to three generations into a C57BL/6 background) of lines TG27 (28 WT: f, $n=15, \mathrm{~m}, n=13 ; 27$ TG: f, $n=10, \mathrm{~m}, n=17$ ) and TG24 (22 WT: $\mathrm{f}, n=$ $15, \mathrm{~m}, n=7 ; 15$ TG: $\mathrm{f}, n=4, \mathrm{~m}, n=11$ ) were analyzed for motor function using several methods: beam balance test, traction, loaded grid, and hindlimb extension reflex (Barnéoud et al., 1997), rotarod performance using two test protocols (Clark et al., 1997; van der Putten et al., 2000), gait analysis (Hruska et al., 1979), and open field activity. Animals were tested every 4 weeks from 11-43 weeks of age. A separate group of TG27 mice (15 WT: f, $n=10$, m, $n=5$; 23 TG: f, $n=12$, m, $n=11$ ) was tested weekly. All testing was performed during the same phase of the light cycle and performed blind.

Two-way ANOVA (SYSTAT 8.0 software) with one between-subject factor (genotype) and with repeated measures (age) was used to analyze weight, rotarod, activity, beam balance, and loaded grid data. The Student's-Newman-Keuls test or Student's $t$ test was used for post hoc pair-wise comparison where appropriate. Repeated measurement data with ordinal scores (hindlimb extension reflex, traction test) were modeled and analyzed by mixed-effects ordinal probit regression analysis with random factors (MIXOR software) (Hedeker and Gibbons, 1996). Survival was analyzed using the Kaplan-Meier method; survival times were compared using the log rank test. Differences were considered statistically significant when $p<0.05$ (two tailed). Because sex had no statistical effect, the data were pooled. All mean values are expressed as mean \pm SEM unless stated otherwise.

Immunohistochemistry and histology. The following stainings were as described: PN-1 (except that antibody incubation was for $3 \mathrm{~d}$ ) (Niclou et al., 1998); microglia (type VI horseradish peroxidase-conjugated lectin of Griffonia simplicifolia (Sigma, St. Louis, MO) (Monnet-Tschudi et al., 1995); anti-Islet-1 (1:500, Developmental Studies Hybridoma Bank, University of Iowa, Iowa City, IA) (Thor et al., 1991); $775^{\text {NTR }}$ and $2 \mathrm{H} 3$ neurofilament [1:1000 (courtesy of Dr. L. F. Reichardt, Howard Hughes Medical Center, University of California, San Francisco, CA) and 1:250 (Developmental Studies Hybridoma Bank), respectively] (Love and Thompson, 1998); the silver-esterase reaction [Pestronk and Drachman (1978), as modified by van der Putten et al. (2000)]; and NADH histochemistry (Filipe and Lake, 1990). Standard procedures were used for hematoxylin/eosin and Nissl (cresyl violet or Mayer's Hemalum) staining. Immunohistochemistry was on fresh-frozen, Bouin's fixed tissue or tissue prepared from $4 \%$ paraformaldehyde-perfused mice using standard procedures. Fixed tissue was immersed in $30 \%$ sucrose/PBS overnight at $4^{\circ} \mathrm{C}$ before embedding in Tissue-Tek OCT (Sakura Finetek Europe., Zoeterwoude, Netherlands) and flash frozen at $-40^{\circ} \mathrm{C}$ in isopentane. Other primary antibodies included SMI-32 and SMI-31 [1:1000 for Vibratome $(40-60 \mu \mathrm{m})$ and 1:200 for cryostat $(30 \mu \mathrm{m})$ sections (Sternberger Monoclonals, Lutherville, MD)] and glial fibrillary acidic protein (GFAP) (1:4000; Dako, Glostrup, Denmark). Usual procedures were followed except that Vibratome sections were incubated with pri- mary antibodies overnight at room temperature, and spinal cord sections were pretreated in cold $\left(-20^{\circ} \mathrm{C}\right)$ methanol for $20 \mathrm{~min}$ before incubation with $0.01 \%$ saponin added to the usual blocking buffer (3\% normal serum $/ 0.3 \%$ Triton X-100/PBS). The primary antibodies were visualized by Vectastain ABC kit (Vector Laboratories, Burlingame, CA) and developed with 4-chloro-1-naphthol and $\mathrm{H}_{2} \mathrm{O}_{2}$ or Alexa 488- or 546conjugated anti-rabbit or anti-mouse IgGs (1:1000; Molecular Probes, Eugene, OR); motor endplates were revealed by rhodamine-conjugated $\alpha$-bungarotoxin (1:500; Molecular Probes).

WT and TG littermate pairs (two to four), essentially all backcrossed for four or more generations, were used for each staining. Sections were processed under identical conditions to allow comparison. Controls with primary antibodies omitted or replaced with irrelevant antibodies allowed background comparison. Results from WT littermates of TG27 and TG24 were indistinguishable. No differences were detected between transgenic TG27 animals backcrossed into either C57BL/6 or BALB/c. For TG24, the histology was performed on animals backcrossed into $\mathrm{BALB} / \mathrm{c}$.

Retrograde labeling. To retrograde label corticospinal projection neurons, the spinal cords of anesthetized mice (fentanyl citrate, $0.189 \mathrm{mg} / \mathrm{kg}$, fluanisone, $6 \mathrm{mg} / \mathrm{kg}$, midazolam, $6 \mathrm{mg} / \mathrm{kg}$, i.p.) were exposed at thoracic level T8 and/or lumbar level L2, and $1 \mu \mathrm{l}$ of $2 \%$ Fluorogold or 2-4\% Fast Blue in saline was injected from a Hamilton syringe through a glass capillary to a depth of $500 \mu \mathrm{m}$ below the dura of TG27 and WT littermates that were either 12 weeks of age (WT, $n=3$; TG, $n=3$ ) or older than 1 year (WT, $n=3$; TG, $n=3$ ). Injection sites were confirmed by fluorescence microscopy. At $7 \mathrm{~d}$, animals were perfused with $4 \%$ paraformaldehyde $/ 5 \%$ sucrose/PBS; $20 \mu \mathrm{m}$ cryostat sections were prepared.

Cell counts. Cell density measurements were made on regularly spaced nonadjacent hemalum-stained sections using a Leitz DMR microscope equipped with a Diagnostics Instrument SPOT-RT camera. Cells with nuclear diameters $>7 \mu \mathrm{m}$ and clearly focused nucleoli were scored in a $65 \times 85 \mu \mathrm{m}$ sector (4-14 cells) superimposed on the projected live image. The $z$-axis distance of the focal plane (between 4 and $8 \mu \mathrm{m}$ ) was read from the microscope. The starting point was always in the primary motor cortex, and two additional fields were randomly sampled within the motor/somatosensory cortex. The average number of large cells per sector was determined for each animal ( 18 sectors; $>150$ cells). It was critical to compare identically processed littermates. Counting of retrograde-labeled neurons was done on photographs taken of the entire labeled field per hemisphere from six evenly spaced sections throughout the labeled region per animal.

Amoeboid microglia were counted in serial transverse sections taken every $200 \mu \mathrm{m}$ throughout the entire cervical-thoracic-lumbar region of the spinal cord. Two pairs of littermates were analyzed at postnatal $(\mathrm{P})$ days $0,5,10,15$, and 20 , and at $4,6,8,10,12,14,16,18,28$, and 60 weeks of age. A total of 50-60 sections per animal was counted; results were expressed as the number of amoeboid microglia per section of either two TG or two WT littermates per age. Large neurons with distinct nucleoli were counted following the criteria described in Oppenheim et al. (1989). Anti-Islet-1- or cresyl violet-stained nonadjacent transverse sections throughout the cervical and lumbar regions of two pairs of TG and WT littermates were sampled. The counting $(>200$ cells per animal) was performed in the better-preserved ventral horn. All mean values expressed are as mean \pm SEM.

Epicranial sensory evoked-potential recordings. Epicranial recordings of evoked potentials in response to whisker stimulation were essentially done as described previously (Troncoso et al., 2000). Briefly, 12-week- or 6-month-old wild-type ( $n=7$ and $n=10$, respectively) and TG27 ( $n=8$ and $n=10$, respectively) littermates, backcrossed for nine or more generations into a C57BL/6 background, were placed in a stereotaxic device under pentobarbital anesthesia $(60 \mathrm{mg} / \mathrm{kg}$, i.p.). An array of five equidistant electrodes was positioned epicranially over the skull from anterior-posterior (AP) +1 and lateral (L) 1.5 to AP -3 and $\mathrm{L} 3.5$, related to bregma. Field potentials were recorded arising from the sensory and facial motor cortex in response to a minimal electromechanical deflection of all vibrissae from the contralateral whisker pad. Spatiotemporal mappings of the evoked potentials created after signal processing represent the average of $\sim 20$ responses. Data were evaluated using the Student's $t$ test; differences were considered statistically significant when $p<0.05$ (two tailed). All mean values are expressed as mean \pm SEM. 

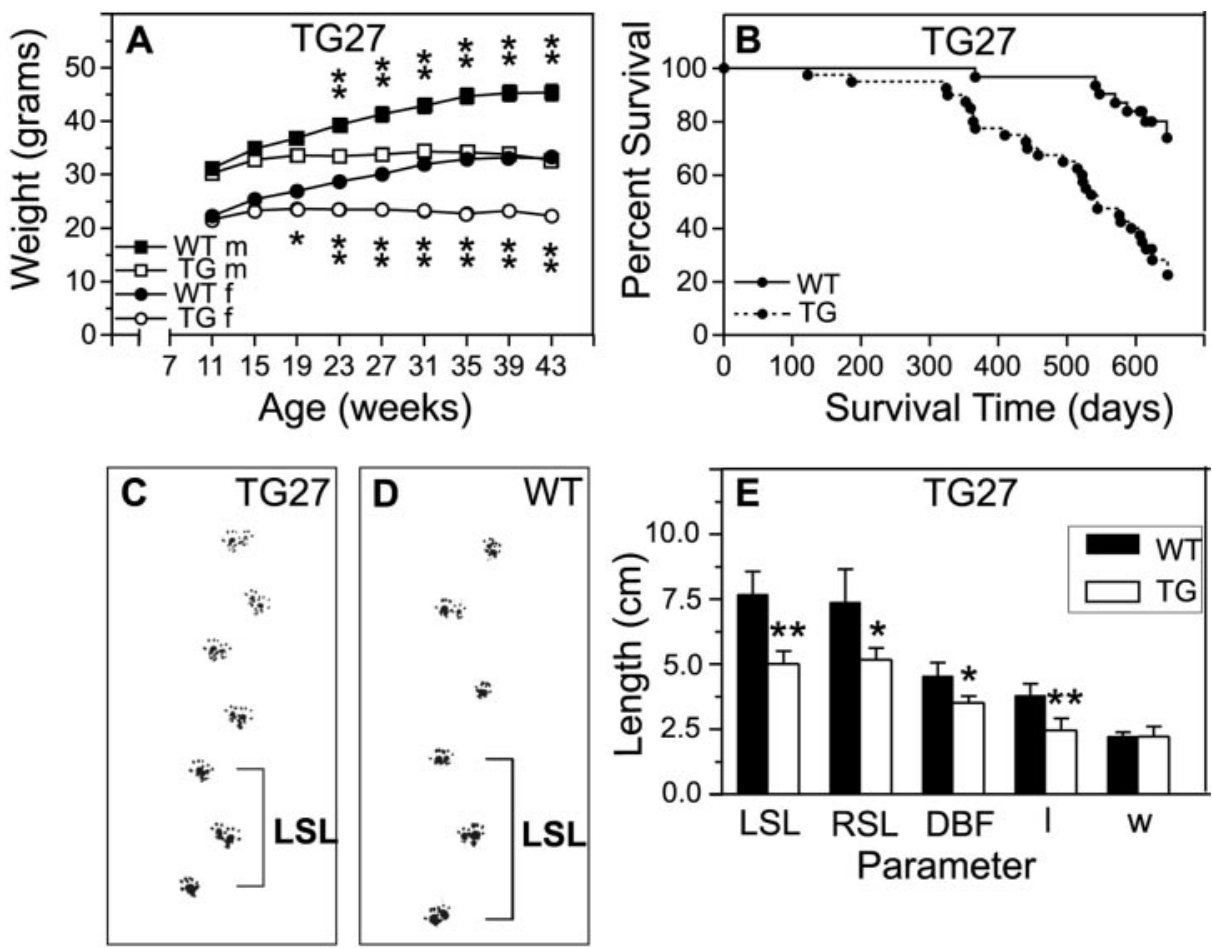

Figure 1. Clinical symptoms in PN-1 overexpressing mice include an age-dependent reduced body weight of TG27 (TG) compared with their wild-type $(W T)$ littermates $(A)$ $\left({ }^{*} p<0.05,{ }^{*} p<0.0001\right.$; symbols indicate the mean \pm SEM) and a reduced survival rate for TG27 compared with wild-type littermates $(B)$. An analysis of footprint patterns of 6-monthold TG27 $(C)$ and wild-type $(D)$ littermates showed that all parameters related to the stride length were significantly reduced in TG27 mice. $L S L$, Left stride length; $R S L$, right stride length; $D B F$, base of support; $l$, distance of the right to interposed left hindfoot print; $w$, width of the stride (female data shown in $E ;{ }^{* *} p<$ $0.01,{ }^{*} p<0.05$; bars represent the mean $\pm \mathrm{SD}$ ). In addition, the hindlimb extension reflex was abnormal in $\mathrm{PN}-1$ transgenic mice as seen in the pictured 7-month-old TG27 mouse $(F)$ but not in its wild-type littermate $(G)$. Scoring over age shows a significant degree of abnormal reflex in both TG27 $(H)$ and TG24 $(I)$ mice (tightly clasped hindlimbs were scored as 2; $p<$ 0.001 , for both lines; symbols indicate the mean \pm SEM). See Materials and Methods for number of mice tested.
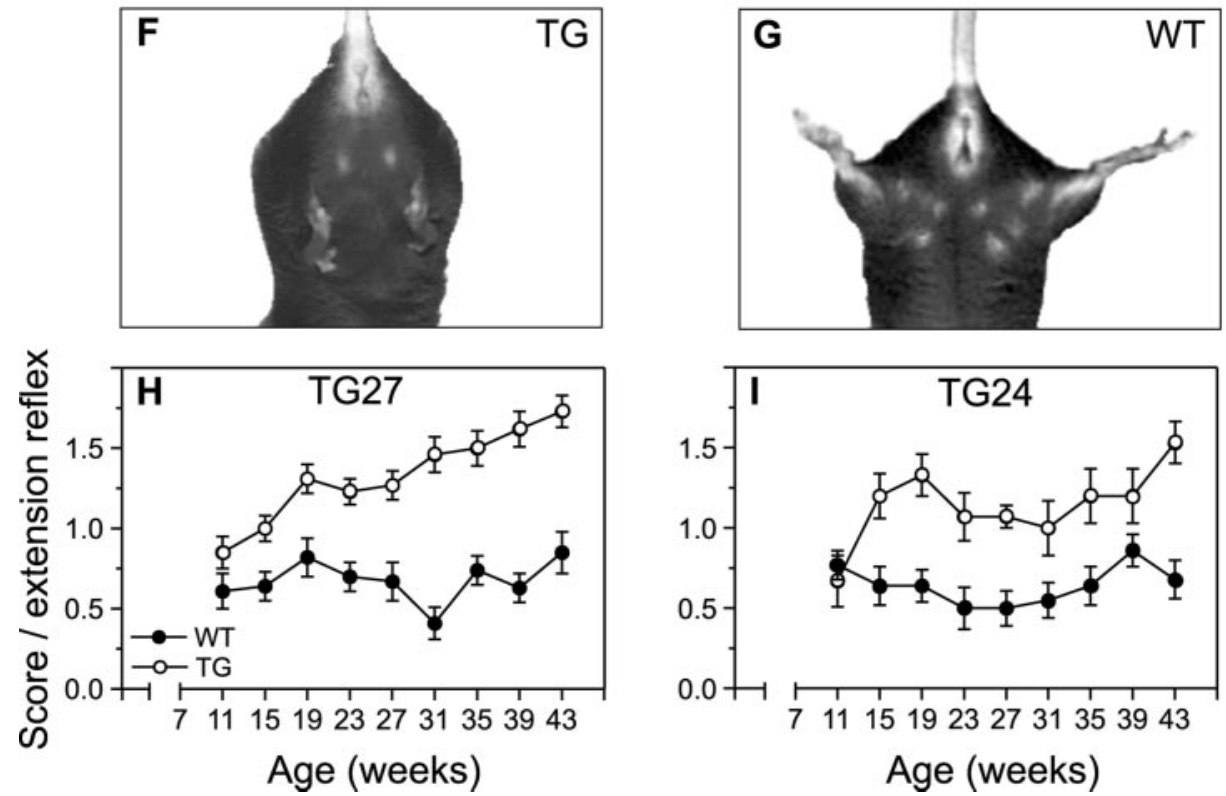

\section{RESULTS}

\section{$\mathrm{PN}-1$ overexpressing mice develop general pathological symptoms}

To examine the consequences of a disturbed extracellular proteolytic activity, several lines of mice with CNS neuronal overexpression of rat PN-1 under the control of the mouse Thy 1.2 promoter were generated (Lüthi et al., 1997). Lines TG27 and TG24 [T2 in Lüthi et al. (1997)] with the highest levels of PN-1 expression were chosen for in-depth analysis.

TG27 and TG24 mice and their respective wild-type littermates behaved similarly for the first 2 months. With age, TG27 mice developed progressive abnormalities. By 6 months, they exhibited kyphosis (hunchback posture), a ruffled coat appearance, and blepharitis (inflammation of the eyelid). Their weight gain was normal until 15 weeks, after which a reduced body weight ( $30 \%$ by 43 weeks) was evident compared with control littermates (genotype by age interaction: females: $F=28.96, p<0.0001$; males: $F=33.21, p<0.0001$ ) (Fig. $1 A$ ). Life expectancy was also affected; the relative risk of dying was approximately five times higher than in the wild-type group $\left(\chi^{2}=20.51 ; p<0.0001\right)$ (Fig. $1 B)$. Males and females were equally affected. No significant difference in weight loss or survival was found for TG24 mice (data not shown). Gait abnormalities were found in TG27 (Fig. $1 C-E$ ) but not TG24 (data not shown) mice. An abnormal hindlimb extension reflex was the earliest observed neurological symptom in both lines: a progressive impairment for TG27 (genotype 


\section{Beam Balance}

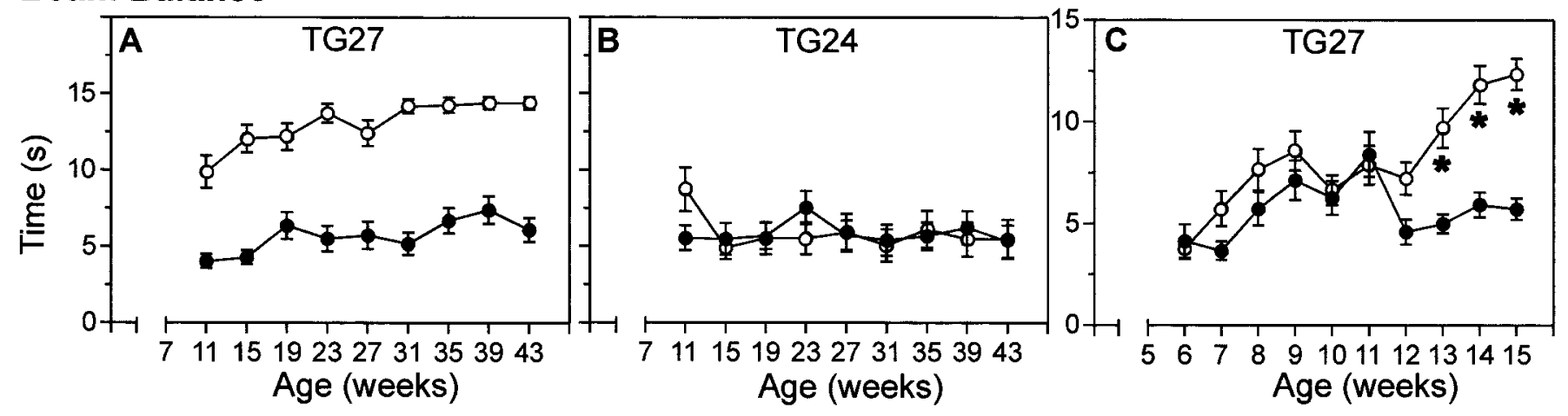

\section{Loaded Grid}

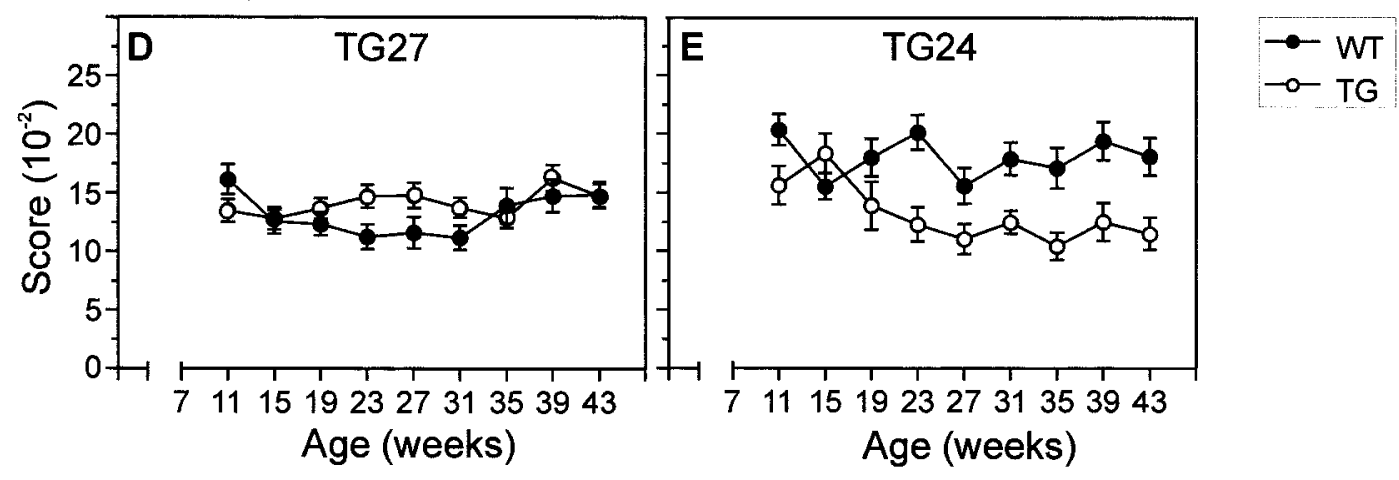

Figure 2. Impaired motor function in PN-1 overexpressing mice was shown in the beam balance performance of TG27 mice $\left(A, p<0.0001 ; C\right.$, ${ }^{*} p<$ 0.001 ) but not TG24 $(B)$ mice (a fall was scored as $15 \mathrm{sec}$ ) and in the loaded grid test where a transient change was detected in TG27 mice $(D)$, but a significant and lasting deficit was detected in TG24 $(E, p<0.01)$ mice (symbols indicate the mean \pm SEM). See Materials and Methods for number of mice tested.

by age interaction: $p<0.001)$ and a persistent impairment for TG24 (genotype effect: $p<0.001$ ) mice compared with wild-type littermates (Fig. $1 F-I$ ). Transgenic animals backcrossed into a BALB/c background also exhibited an abnormal hindlimb extension reflex.

\section{Quantitative assessment of motor deficits in PN-1 transgenic mice}

These results led us to investigate their motor behavior in more detail over an 8-month period. To reduce effects arising from interference with nearby genes after transgene insertion or from the genetic background, the study was performed with hemizygous TG27 and TG24 mice backcrossed into C57BL/6 and their respective wild-type littermates. In the open field test, all mice displayed similar levels of habituation to the new environment and comparable activity (data not shown).

Beam balance, in which a mouse learns to cross a narrow beam to reach a platform, and rotarod tests were used to assess speed and coordination of movement as well as motor learning. The beam balance test clearly demonstrated a motor impairment of TG27 $(F=213.3 ; p<0.0001)$ (Fig. $2 A)$ but not of TG24 $(F=$ $0.25 ; p=0.62$ ) (Fig. $2 B$ ) mice compared with wild-type littermates. The hindpaws of TG27 mice tended to lock in a fixed spastic posture while on the beam, and by 31 weeks, almost every mouse fell. An additional group, evaluated from the age of 6 weeks, developed the deficit at 12-13 weeks (genotype by age interaction: $F=2.33 ; p=0.018$ ) (Fig. $2 C$ ). The delayed onset in the second cohort may be attributable to earlier training and practice. The behavioral deficit was not dependent on the genetic background: TG27 mice backcrossed into BALB/c for nine generations showed a similar phenotype (data not shown). No significantly impaired performance was observed in two distinct protocols of the rotarod test for either TG27 or TG24 mice (data not shown). The difference in performance of TG27 mice in the beam balance and rotarod tests probably reflects the difference in motivation and type of movement demanded by the two tasks.

Muscle strength of forelimbs and hindlimbs was evaluated using loaded grid and traction tests. TG27 mice showed a significant transient change in performance with the loaded grid test (genotype by age interaction: $F=3.53 ; p=0.001$ ), although no other general difference was evident (genotype effect: $F=1.60$; $p=0.21$ ) (Fig. 2D). TG24 mice showed a significantly lower performance in the loaded grid test than control littermates (genotype effect: $F=7.51, p=0.01$; genotype by age interaction: $F=2.64, p=0.008$ ) (Fig. $2 E$ ). This deficit in muscle strength was confirmed by the traction test for TG24 (genotype effect: $p=$ 0.02 ) but not TG27 (data not shown) mice. Taken together, the behavioral tests demonstrate that mice overexpressing PN-1 have significant but line-dependent motor impairments of varying severity.

\section{Neurogenic muscle atrophy and axonopathy in PN-1 transgenic mice}

Because of the motor deficits revealed by footprint patterns, muscle weakness, and beam balance tests, we examined the hindlimb. Gastrocnemius muscle dissected from aged (i.e., between 16 and 24 months) TG27 mice was noticeably smaller and redder than that from wild-type littermates. Histopathological examina- 

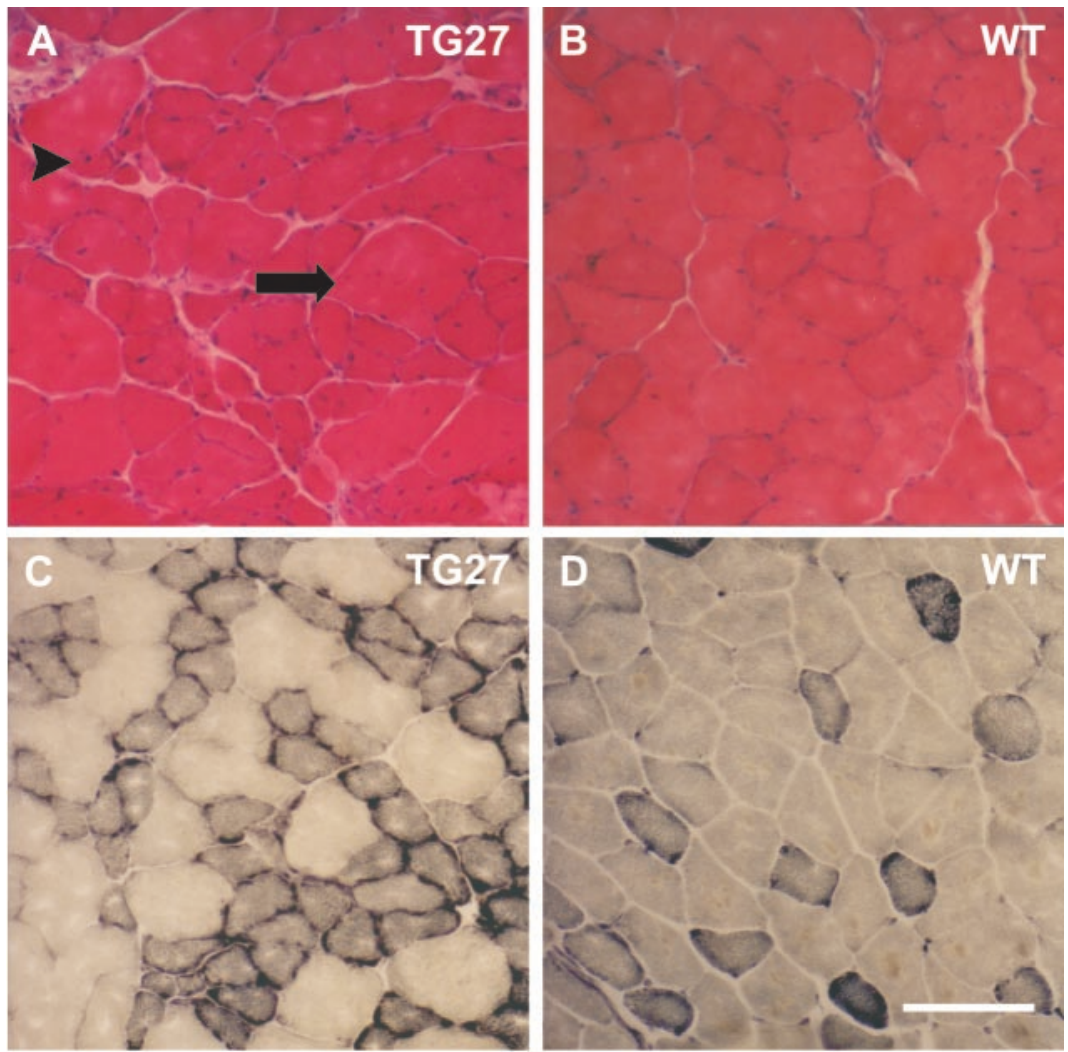

Figure 3. Neurogenic muscle atrophy and axonopathy in PN-1 transgenic mice. $A-D$, Hematoxylin/eosin-stained ( $A$, $B)$ and NADH histochemically stained $(C, D)$ cross sections of gastrocnemius muscle. Small angular atrophic muscle fibers (arrowhead) intermingled with hypertrophic muscle fibers (arrow), indicating neurogenic muscle atrophy in TG27 $(A)$, are not seen in wild-type $(B)$ littermates. Prominent type I slow (dark) and type II fast (light) fiber clustering indicates chronic denervation and reinnervation in TG27 muscle $(C)$, unlike the normal pattern of randomly scattered fibers from wild-type littermate muscle $(D) . E-H$, p $75^{\text {NTR }}$ immunoreactivity in longitudinal sections of gastrocnemius muscle. Neuromuscular junctions are visualized by $\alpha$-bungarotoxin binding $(E-H$, red $)$. Strong anti-p $75^{\text {NTR }}$ staining (green) is seen at the neuromuscular junctions of 14-week-old TG27 mice $(E, H)$ and 12-week-old TG24 mice $(F)$ compared with wild-type $(G)$ littermates, as well as along nerve fibers $(F)$ and revealed by $2 \mathrm{H} 3$ antineurofilament staining $(H$, also red). $I, J$, Silver-stained longitudinal muscle sections reveal thick, presumably overcompensating nerve fibers along with thin, degenerated ones in some nerve bundles of aged TG27 mice $(I)$ but not wild-type littermates $(J) . K-N$, Transverse sections of lumbar ventral roots. More p $75^{\mathrm{NTR}}$ immunoreactivity (green) is seen in aged TG27 $(K)$ than in wildtype $(L)$ littermates. Neurofilament (SMI-32 antibody) immunoreactivity is similar in TG27 $(M)$ and wild-type $(N)$ littermates. Scale bars: $A-D$ (shown in $D$ ), $100 \mu \mathrm{m}$; $E-H$ (shown in $H$ ), $50 \mu \mathrm{m} ; I, J$ (shown in $J$ ), $25 \mu \mathrm{m} ; K-N$ (shown in $N$ ), $20 \mu \mathrm{m}$.
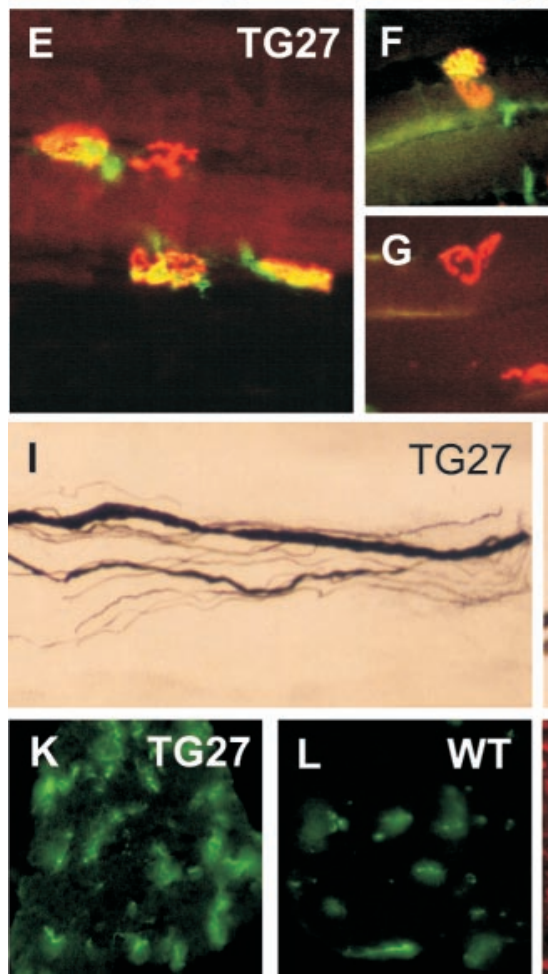
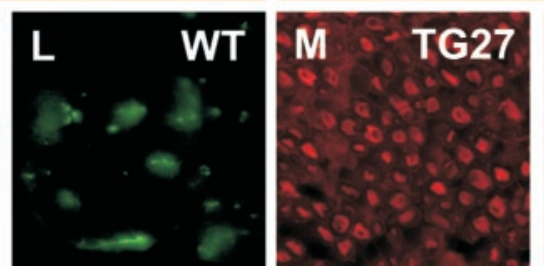

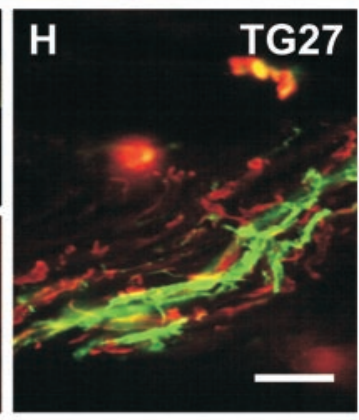

J

WT
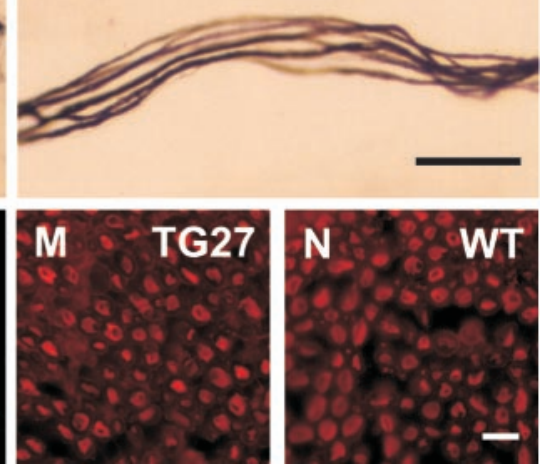

tion revealed typical signs of chronic denervation and reinnervation, with irregularly shaped and clustered fibers (Fig. 3A-D). The dark patches of type I slow fibers represent reinnervation of denervated fibers by sprouting slow axons (Anderson, 1985). TG24 mice had mild muscle histopathological abnormalities (data not shown). The behavioral deficits of the two transgenic lines thus parallel the degree of neurogenic muscular atrophy.
The time course of these changes in innervation was investigated with the low-affinity neurotrophin receptor $\left(\mathrm{p} 75^{\mathrm{NTR}}\right)$ that is upregulated in Schwann cells during axonal degeneration caused by axotomy and peripheral neurotoxicity (Taniuchi et al., 1986; Roberson et al., 1995). p $75^{\text {NTR }}$ immunoreactivity was found at the neuromuscular junction and along nerve fibers in TG27 and TG24 mice (Fig. $3 E-H$ ). No staining was detected in 
TG27 at 10 weeks, whereas $\sim 16 \%$ of the $\alpha$-bungarotoxinidentified motor endplates were labeled by 14 weeks. Thus axonSchwann cell contact is affected in both TG27 and TG24 animals and coincides with the onset of the abnormal hindlimb reflex. Additional evidence that the muscle atrophy was associated with axonopathy came from silver staining of gastrocnemius muscle from TG27 animals (Fig. 3I, $J$ ). Proximal axons were also affected. Increased p $75^{\mathrm{NTR}}$ immunoreactivity was found in ventral (Fig. $3 K, L$ ) but not dorsal roots (data not shown), suggesting that motor but not sensory innervation is affected at this level. However, neurofilament immunostaining revealed no obvious difference in the axon profile of ventral roots (Fig. $3 M, N$ ). In summary, PN-1 transgenic mice exhibit axonopathy by 14 weeks of age and develop typical signs of a chronic neurogenic disease of the denervating type.

\section{Neuropathological findings in the spinal cord of $\mathrm{PN}-1$ transgenic mice}

To further investigate the cellular basis of the motor deficits, we first examined the extent of $\mathrm{PN}-1$ overexpression in spinal cord from the two transgenic lines. The weak PN-1 immunostaining in wild-type littermates was in contrast to the strong widespread staining in both TG27 and TG24 mice (Fig. $4 A-C$ ). The onset and level of transgene expression were comparable in both lines (data not shown).

Astrogliosis and microgliosis, typical neuropathological signs, were found. Numerous reactive astrocytes with enlarged cell bodies and thick, numerous processes were detected with an antibody to GFAP (Fig. $4 D-F$ ). These reactive astrocytes were already evident in TG27 mice from 8 weeks. Microglia, with the typical amoeboid shape of reactive cells revealed by $G$. simplicifolia B4 isolectin staining (Streit and Kreutzberg, 1987), were also found in TG27 mice (Fig. 4G, insets). A time course analysis revealed transient microgliosis reaching a peak at 12-14 weeks (Fig. 4G), corresponding to the onset of the beam balance deficit. No obvious segmental or regional distribution for either astrogliosis or microgliosis was found in the spinal cord. To determine whether these neuropathological changes were associated with neuronal loss, the average number of Islet-1-positive motor neurons (Thor et al., 1991) per ventral horn section of aged PN-1 transgenic mice and littermates was compared. No major difference was detected: $2.9 \pm 0.2(n=186$ sections $)$ and $3.0 \pm 0.1(n=$ 193 sections) cells per section for TG27 and wild-type littermates, respectively, and $2.9 \pm 0.2(n=189$ sections $)$ and $2.9 \pm 0.1(n=$ 190 sections) cells per section for TG24 and wild-type littermates, respectively. Quantification of cresyl violet-stained sections confirmed these results (data not shown). We cannot exclude the possibility, however, that the counting method used would not detect a small subpopulation of motor neurons that could be specifically at risk, e.g., motor neurons with long axons innervating distal musculature. Furthermore, no signs of degeneration such as swollen perikarya, depleted rough endoplasmic reticulum, or eccentrically positioned nuclei were found in the motor neurons of either TG27 or TG24 mice (data not shown).

The presence of astrocytes and microglia in white as well as gray matter suggested that fiber tracts might have been affected. This was investigated with SMI-32 antibody, which reveals nonphosphorylated neurofilament-heavy subunit (NF-H) in degenerating axons (Leifer and Kowall, 1993) and recognizes motor neurons in the spinal cord (Tsang et al., 2000). Staining was normal except for the positively stained large fibers of the lateral and ventral funiculus in wild-type mice (Fig. $4 H$ ) that were only

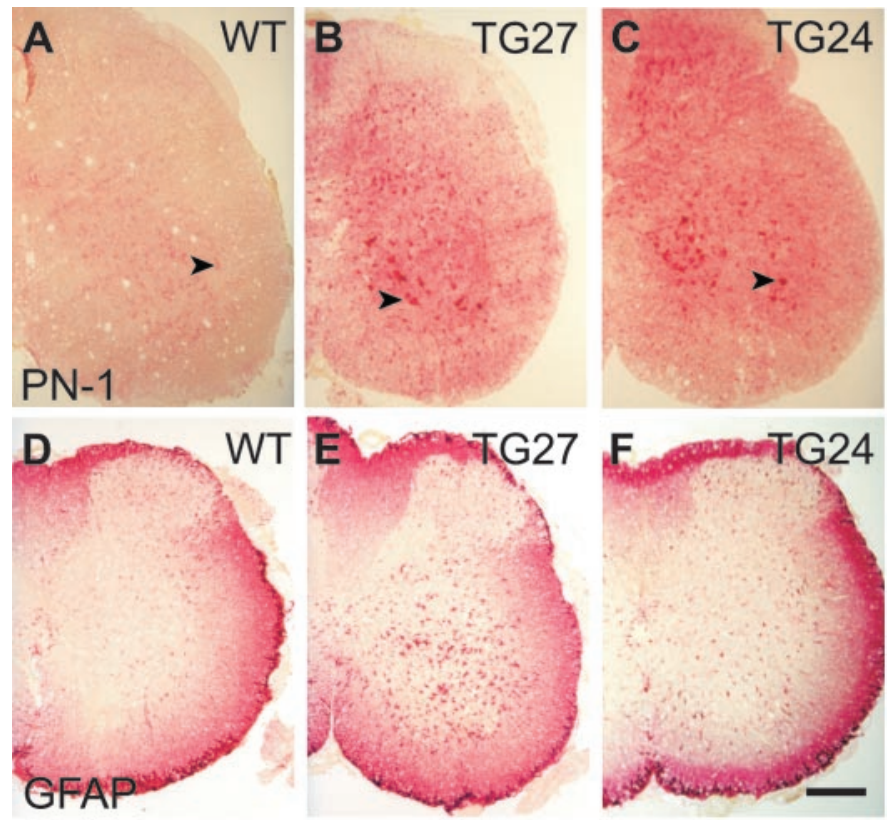

G
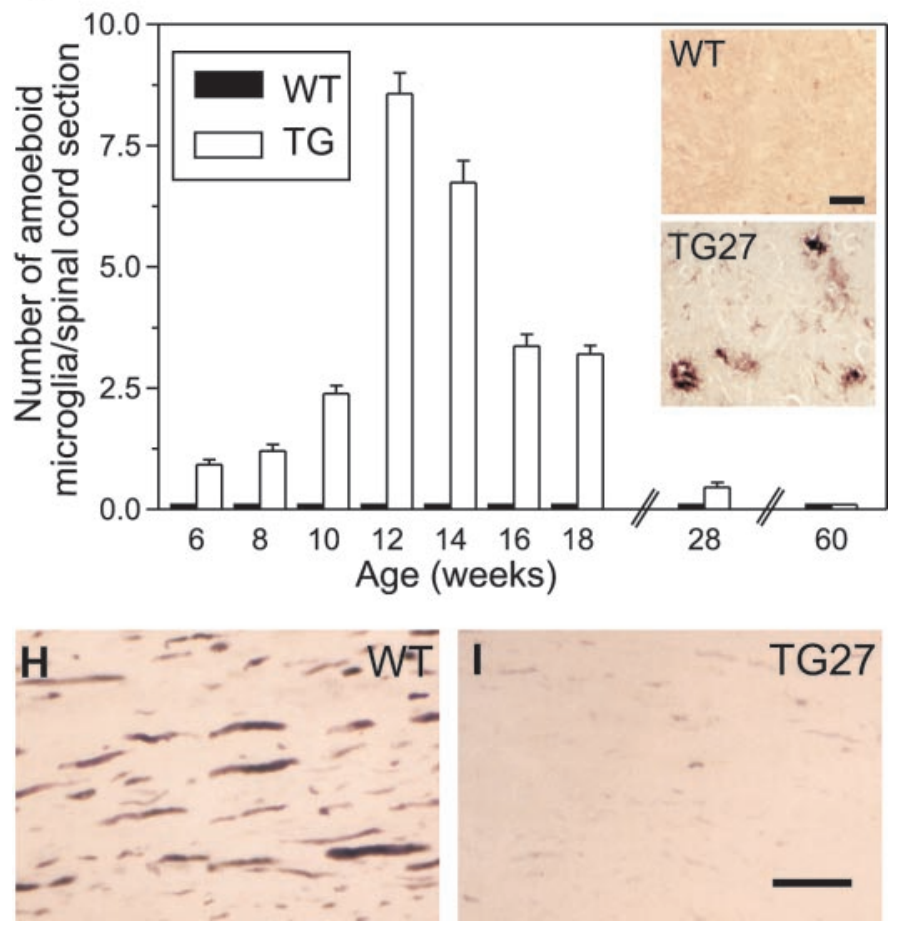

Figure 4. Neuropathological findings in the spinal cord of PN-1 overexpressing mice. $A-F$, Transverse spinal cord sections of aged littermates stained with an antibody to PN-1 $(A-C)$ or GFAP $(D-F)$. Weak and limited PN-1 cellular immunostaining is seen in wild-type $(A)$ compared with TG27 $(B)$ and TG24 $(C)$ mice; motor neurons are indicated by arrowheads. Far fewer GFAP-positive reactive astrocytes are seen in wild-type $(D)$ than in TG27 $(E)$ and TG24 $(F)$ mice. $G$, Transient microglial activation in TG27 mice with a peak at 12-14 weeks; insets show isolectin staining of reactive microglia in TG27 but not in wild-type littermates. Bars represent mean \pm SEM. $H, I$, Nonphosphorylated NF-H immunoreactivity in longitudinal spinal cord sections of aged wild-type $(H)$ is strongly reduced in TG27 $(I)$ littermates (ventral funiculus is shown). Scale bars: $A-F$ (shown in $F$ ), $200 \mu \mathrm{m} ; G$, insets, $50 \mu \mathrm{m} ; H, I$ (shown in $I$ ), $50 \mu \mathrm{m}$. 
weakly or not detected in the ascending and descending tracts of their TG27 littermates (Fig. 4I); this difference was already evident at 14 weeks. Similar results were found with antibodies to phosphorylated NF-H (SMI-31) and neurofilament-M subunit (NF-M) (2H3) (data not shown). This could represent a decreased level of the neurofilaments or a masking of epitopes. There was no pronounced decrease in the white matter of transgenic mice, nor were changes observed in the corticospinal tract, composed of small-caliber fibers and located in the dorsal funiculus (data not shown). Immunostaining with SMI-31, which labels axonal spheroids and cell bodies of neurons in spinal cord and brain of amyotrophic lateral dystrophy patients (Manetto et al., 1988; Troost et al., 1992), did reveal an age-dependent increase in the number of immunopositive neuronal soma in TG27 compared with wild-type littermates (data not shown). Staining in TG24 animals appeared normal (data not shown). The behavioral deficits and the astrogliosis observed in TG24 and TG27 mice correlate with high PN-1 levels found in the spinal cord. The onset of the beam balance phenotype, found only in TG27, correlates with the peak of transient microgliosis and an altered pattern of neurofilament staining. Taken together, these results indicate a generalized neurodegenerative response that does not affect the number of motor neurons.

\section{Distinct cortical PN-1 expression in the different lines of transgenic mice}

Because there was no pronounced difference in the expression pattern of PN-1 in the spinal cords of TG24 and TG27 mice that could account for the phenotypic differences, we compared other areas of the CNS. Both immunoblot analysis (data not shown) and protease inhibition assays indicated similar levels of transgenic PN-1 protein; threefold more inhibitory activity was found in homogenates of transgenic than in wild-type cerebral cortex [TG27: 1.6 vs 0.5 pmol equivalent $\mathrm{PN}-1$ per milligram of protein; and as shown earlier for TG24: 2.0 vs 0.6 pmol equivalent PN-1 per milligram of protein (Lüthi et al., 1997)].

A disparate localization of $\mathrm{PN}-1$ protein, however, was found in the transgenic lines as shown for P20 animals in Figure $5 A-C$. Compared with wild-type littermates (Fig. 5A) (Mansuy et al., 1993), PN-1 immunostaining was intense and concentrated in cells of layers V and VI throughout the whole cerebral cortex of TG27 mice (Fig. 5B) from P15. In contrast, strong and widespread immunostaining was found in TG24 mice (Fig. $5 C$ ) by the first postnatal week. This spatial difference in the protein distribution must therefore result in a higher local PN-1 activity. Immunoblot analysis of cerebral cortex homogenates also revealed the different time course of PN-1 expression. In TG24 mice, the signal for the transgenic protein was already apparent by $\mathrm{P} 7$ and peaked by P14, whereas in TG27 mice it was detected by P14 and peaked by P21 (data not shown) at a stage in cortical development characterized by the formation of projections followed by collateral elimination (Stanfield et al., 1982). In situ hybridization studies confirmed that both the time course of expression and the regional distribution of transgenic PN-1 mRNA, as for the protein, are different in these two lines (data not shown). Such variable but line-specific patterns of expression have been described for the Thy 1.2 promoter (Caroni, 1997; Feng et al., 2000). These results suggest that the range of motor deficits in the two transgenic lines is related to their different patterns of transgenic PN-1 expression in the cerebral cortex.

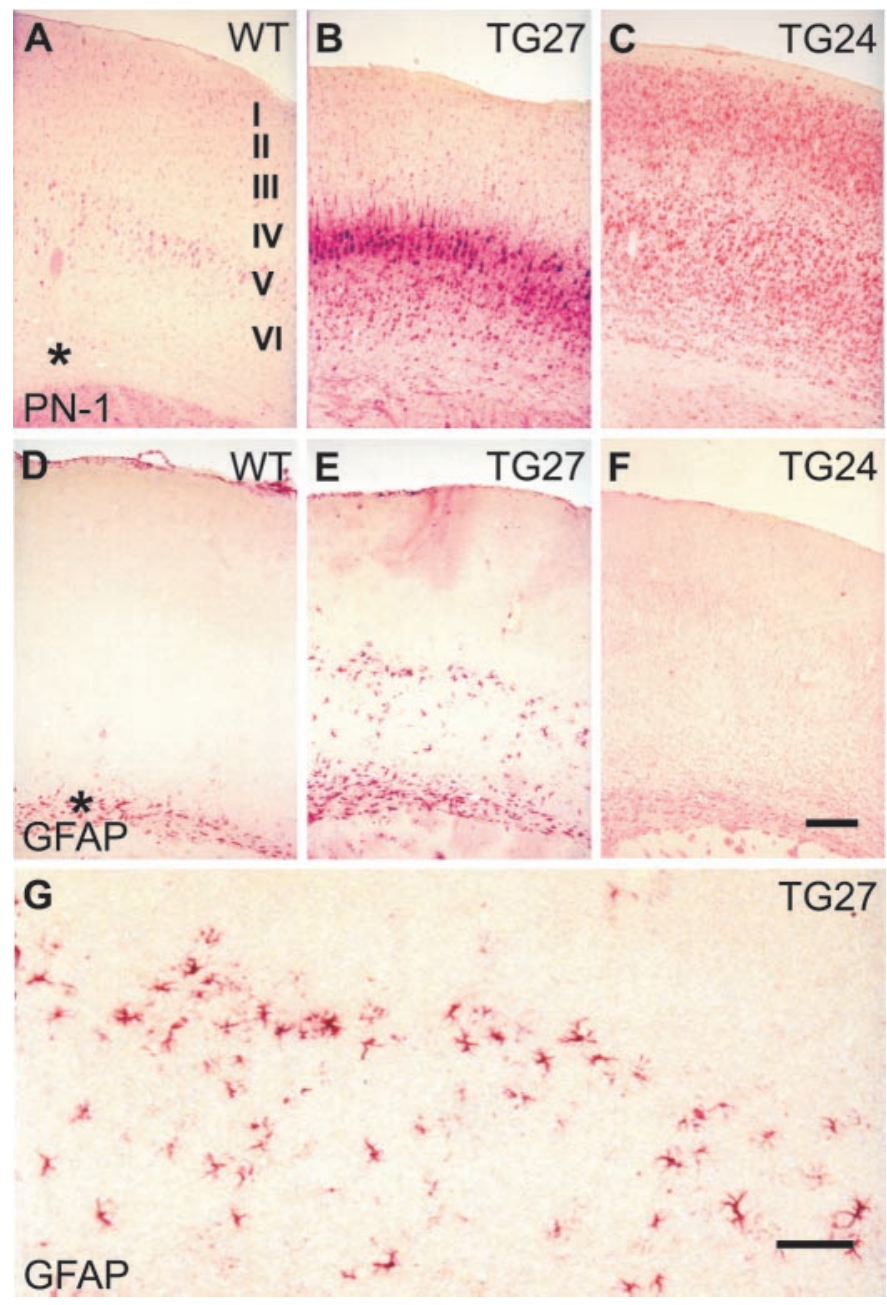

Figure 5. PN-1 and GFAP immunoreactivity in cortex of TG27 and TG24 mice. $A-G$, Coronal brain sections from the primary motor/somatosensory cortex of littermates stained with an antibody to PN-1 at P20 $(A-C)$ or GFAP at 12 weeks $(D-G)$. Endogenous PN-1 is mainly in layer $\mathrm{V}$ pyramidal cells of wild-type mice $(A)$. $\mathrm{PN}-1$ overexpression is strong and regionally restricted in TG27 $(B)$, whereas it is widespread in TG24 $(C)$ mice. Many GFAP-positive reactive astrocytes are found in layers $\mathrm{V}$ and VI of TG27 ( $E$; higher magnification in $G$ ) but not wild-type $(D)$ or TG24 $(F)$ mice. The cortical layers are indicated by $I-V I$; asterisk indicates corpus callosum. Scale bars: $A-F$ (shown in $F$ ), $200 \mu \mathrm{m} ; G, 100 \mu \mathrm{m}$.

\section{Neuropathological findings in the brain of $\mathrm{PN}-1$ transgenic mice}

Cortical PN-1 overexpression was accompanied by astrogliosis in TG27 but not in TG24 mice as shown for 12-week-old animals in Figure $5 D-G$. This intense astrocytic response was limited to the areas of transgene expression and was age-dependent, starting at 10-12 weeks and increasing with age. Although reactive astrocytes were detected outside of the cortex in wild-type mice, more were found in some fiber tracts, the thalamus, and the brainstem of TG27 mice (data not shown). No difference was seen in the cerebellum. This major and early pathological difference correlated with the delayed and intense regional overexpression of PN-1 distinguishing TG27 from TG24 mice (Fig. 5B,C). Some activated microglia were detected in hindbrain structures, such as the cerebellum, pons, and medulla, but not in the cerebral cortex of TG27 mice (data not shown). The cytoarchitecture of the cerebral cortex was maintained, and the large pyramidal cells of 

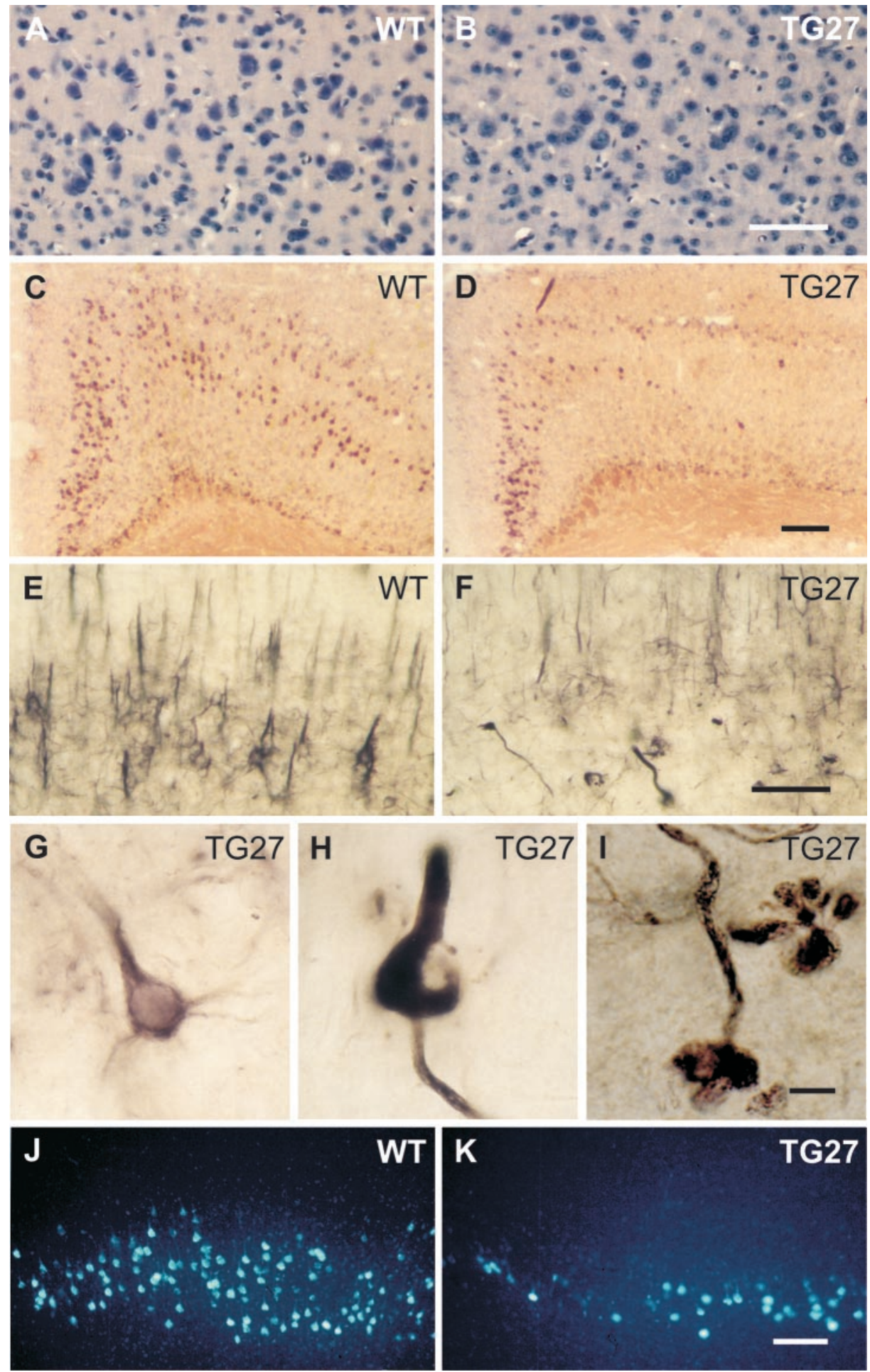

Figure 6. Neuropathological findings in the cortex of TG27 mice. Coronal sections of the hindlimb somatosensory cortex $(A, B, E-I)$ and the primary motor/somatosensory cortex $(C, D$, $J, K$ ) from aged littermates. Hemalum staining of layer $\mathrm{V}$ cells shows no difference between wild-type $(A)$ and TG27 $(B)$ mice. Expression of GAP-43 mRNA detected by in situ hybridization of wild-type $(C)$ is reduced in TG27 $(D)$ mice. Neurofilament immunoreactivity shows typical somatodendritic localization of nonphosphorylated NF-H in a subset of layer V pyramidal neurons of wild-type mice $(E)$; a strikingly different staining pattern is seen throughout the cortex of TG27 mice $(F)$, where normal $(G)$ as well as abnormal $(H)$ pyramidal neurons, some with aberrant process endings $(I)$, are found. Fluorogold retrograde labeling of layer $\mathrm{V}$ pyramidal neurons projecting to the spinal cord in wild-type $(J)$ is reduced in TG27 $(K)$ mice. Scale bars: $A, B, E, F$ (shown in $B, F), 100 \mu \mathrm{m} ; C, D$ (shown in $D$ ), $100 \mu \mathrm{m}$; $G-I($ shown in $I), 12.5 \mu \mathrm{m} ; J, K($ shown in $K)$, $100 \mu \mathrm{m}$. the motor and somatosensory regions looked normal, with no apparent difference in the number of pyramidal neurons (Fig. $6 A, B)$. This was confirmed by the density of large neurons in layer $\mathrm{V}$ of this cortical region in two pairs of 1.5-year-old TG27 and wild-type littermates, namely when survival was already affected. The mean densities were essentially the same for TG27 $\left(29.1 \times 10^{4} \pm 2.9 \times 10^{4}\right.$ and $26.0 \times 10^{4} \pm 0.5 \times 10^{4}$ cells $/ \mathrm{mm}^{3}$; $n=18)$ and wild-type $\left(29.8 \times 10^{4} \pm 1.8 \times 10^{4}\right.$ and $25.7 \times 10^{4} \pm$ $1.9 \times 10^{4}$ cells $\left./ \mathrm{mm}^{3} ; n=18\right)$ mice. This was also found in a third pair of littermates, the brains of which showed less shrinkage as a result of being fixed and embedded differently. The cerebellum and other areas of the CNS also appeared normal.

Futhermore, no evidence of enhanced cellular vulnerability was detected in TG27 mice of various ages using 10 different markers or assays for oxidative damage, stress, or apoptosis (data not shown). Thus we searched for signs of functional disturbance that would be indicative of more subtle damage. Growthassociated protein-43 (GAP-43) mRNA is highly expressed during development and regeneration (Jacobson et al., 1986), whereas in the adult neocortex it is limited to layer $\mathrm{V}$ and deep 

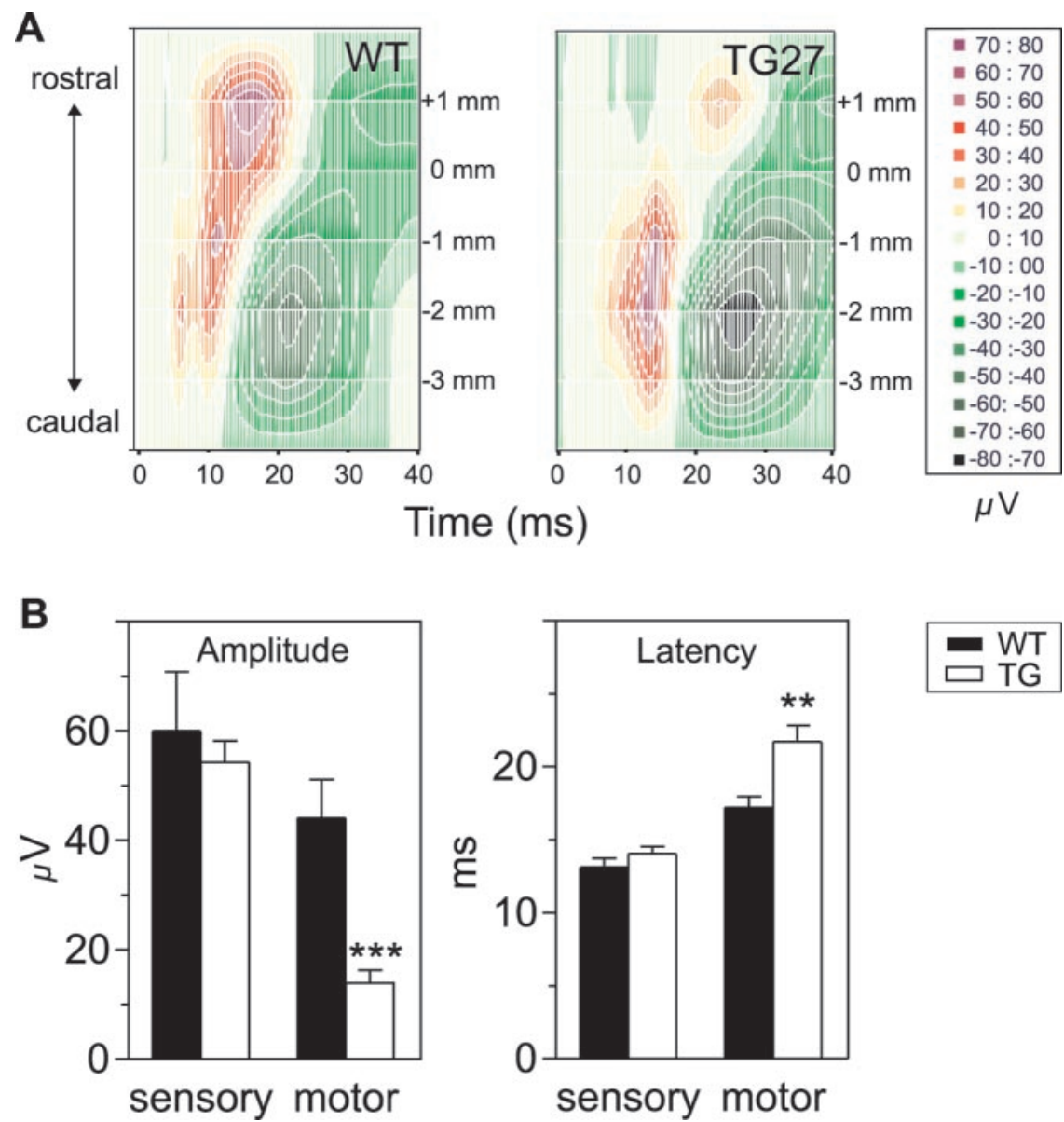

Figure 7. Impairments in motor cortex evoked responses of 6-month-old TG27 mice after whisker stimulation. $A$, Example of spatiotemporal representation of the cortical responses over the sensory barrel cortex (electrode placed at $-2 \mathrm{~mm}$ ) and the delayed response over the motor cortex (electrode placed at $+1 \mathrm{~mm}$ ); amplitudes $(\mu V)$ in color; time $(m s)$ : horizontal axis; the coordinates related to bregma: up, AP +1 ; down, AP $-3(\mathrm{~mm})$ : vertical axis. $B$, Quantitative analysis of collective data. Similar amplitudes and latencies are recorded over the sensory barrel cortex of wild-type and TG27 littermates. Significantly decreased amplitude $(* * * p 0.001)$ and longer latency $(* * p<0.005)$ are recorded over the contralateral motor cortex of TG27 mice. Bars represent mean \pm SEM.

layer VI cells (Fig. 6C) (Jacobs et al., 1993). Using in situ hybridization, a pronounced decrease in GAP-43 expression was detected in TG27 mice (Fig. 6D). This difference was not seen at 10 weeks, the onset of reactive astrogliosis, but at 14 weeks, together with the beam balance deficit. In contrast, GAP-43 expression was similar in aged TG24 and wild-type littermates (data not shown).

The integrity of the cortical pyramidal cells was then investigated at the level of the cytoskeleton. SMI-32 antibody, a somatodendritic marker of a subpopulation of cortical pyramidal cells of layers III and V (Fig. 6E) (Campbell and Morrison, 1989), revealed a strikingly altered $\mathrm{NF}-\mathrm{H}$ distribution throughout the deeper layer $\mathrm{V}$ in TG27 mice (Fig. $6 F-I$ ). Similar results were found with an antibody detecting nonphosphorylated NF-M (data not shown). Layer III pyramidal neurons were unaffected. Although 9-week-old brains appeared normal, changes could be detected by 12 weeks (data not shown). Aged TG24 mice displayed no aberrations. SMI-31 antibody stained a few cell bodies as well as some thickened processes in layer V of aged TG27 but not their wild-type littermates (data not shown). Taken together, these results indicate that pyramidal neurons in TG27 mice are impaired and exhibit neurofilament changes associated with neurodegenerative diseases.

Layer $\mathrm{V}$ pyramidal neurons of the primary motor cortex and the hindlimb/forelimb regions of the primary somatosensory cortex project to the spinal cord. The integrity of their corticospinal projections was evaluated by retrograde tracing. At 12 weeks, no significant difference in the number of labeled cells between three pairs of TG27 and wild-type littermates was found (92 \pm 14 and
$107 \pm 10$ cells per section, respectively; $n=3 ; p=0.4363$ ) Compared with wild-type littermates, reduced labeling was detected in aged TG27 mice (Fig. $6 J, K$ ). This could be the result of axonal degeneration, e.g., reduced axonal transport, or decreased ability to take up dye by axons, and need not be associated with cell loss, as shown by an electrophysiological study demonstrating active pyramidal neurons 1 year after axotomy of the corticospinal tract (Tseng and Prince, 1996). Altogether, these results suggest that a locally restricted and sufficiently high overexpression of PN-1 in cortical layers $\mathrm{V}$ and VI leads to progressive neuropathological changes and neuronal dysfunction without detectable cell loss.

\section{Abnormal evoked responses recorded over the motor cortex of TG27 mice}

To evaluate whether these cytological and tracing data indicated an impact of PN-1 overexpression on cortical physiology, we used a newly developed, noninvasive technique to measure responses to whisker stimulation. Primary sensory evoked potentials over the contralateral sensory barrel cortex and delayed signals over the contralateral facial motor cortex were detected using an epicranial multi-electrode recording system (Fig. 7A) (Troncoso et al., 2000). At 12 weeks, the amplitude of the contralateral responses recorded over both the sensory barrel cortex and the motor cortex did not differ between wild-type and transgenic mice (data not shown). There was, however, a significant increase in the latency of the response recorded over the motor cortex in TG27 compared with wild-type littermates $(24.1 \pm 1.4 \mathrm{msec}$ vs $19.3 \pm 0.6 \mathrm{msec} ; n=8 ; p<0.005)$. The latency for responses 
recorded over the sensory barrel cortex was similar (data not shown). At 6 months, TG27 mice also showed no significant difference from their wild-type littermates in the amplitude ( $p=$ $0.64)$ or latency $(p=0.22)$ of the contralateral responses recorded over the sensory barrel cortex (Fig. $7 B$ ). However, in addition to an increased latency $(p<0.005)$, a significantly decreased amplitude $(p<0.001)$ was recorded over the motor cortex (Fig. 7B). Barrel field cytoarchitecture and peripheryrelated patterning, revealed in tangential sections through layer IV by Nissl and cytochrome oxidase histochemical staining, appeared normal in all aged mice (data not shown). The impairment may be at the level of corticocortical connectivity, motor cortex afferent synapses, or pyramidal neurons and needs to be evaluated further. Nonetheless, these results clearly indicate a progressive deficit in sensorimotor integration, without obvious vibrissae-related sensory dysfunction, in TG27 mice.

\section{DISCUSSION}

The use of the Thy 1.2 promoter to ectopically express or overexpress PN-1 in postmitotic neurons (Lüthi et al., 1997) offered the possibility to explore the long-term consequences of an excess of this serpin in the mature CNS. The two mouse lines studied in detail show symptoms reminiscent of early stages in motor neuron disease but without any detectable cell loss in spinal and cortical motor neurons.

\section{Axonopathy-linked neuronal dysfunction}

The motor problems exhibited by both lines of transgenic mice were associated with axonal dysfunction. Increased $\mathrm{p} 75^{\mathrm{NTR}}$ immunoreactivity was detected in terminal Schwann cells at the neuromuscular junction and along nerve fibers (Fig. $3 E, F, H, K$ ) and followed the time course of motor deficits. This may reflect disturbances in axonal-Schwann cell contact (Taniuchi et al., 1986) resulting from active remodeling at the neuromuscular junction, as substantiated by the changes in distribution of slow and fast muscle fibers in TG27 mice (Fig. 3C). This axonal pathology (as well as the astrogliosis and microgliosis) is not linked to significant spinal or cerebral motor neuron loss. Our results are thus in line with earlier reports indicating that muscle atrophy with axonopathy caused by the overexpression of cytoskeletal proteins is not necessarily associated with a loss of spinal motor neurons (Côté et al., 1993; Xu et al., 1993; Spittaels et al., 1999).

The impaired communication between the sensory and motor cortex detected in TG27 mice during whisker stimulation (Fig. 7) could also be explained by axonal dysfunction after synaptic alterations such as revealed by the decrease in GAP-43 (Fig. 6D), a marker of synaptic plasticity in cortical pyramidal neurons (Jacobs et al., 1993). Axonopathy is indicated by the abnormal nonphosphorylated NF-H immunoreactivity detected in axonlike processes (Fig. 6I). Further evidence for axonal alterations is the reduced retrograde labeling of the layer $\mathrm{V}$ corticospinal cells (Fig. $6 K$ ) and the astrogliosis found in cerebral fiber tracts. The fact that these cellular changes are associated with the beam balance phenotype raises the possibility that dysfunctional long projecting cortical neurons contribute to the development of this specific motor deficit.

\section{PN-1 overexpression-linked neuronal dysfunction}

The difference in the motor deficits observed in TG27 and TG24 mice is most probably ultimately caused by the use of the Thy 1.2 promoter, which is reported to give rise to distinct but reproduc- ible patterns of transgene expression (Caroni, 1997; Feng et al., 2000). TG27 mice have a spatially restricted and delayed high expression of the transgene in the cortex compared with TG24 mice (Fig. 5B,C). It is in this region of higher local PN-1 concentrations that astrogliosis and alterations in cortical neurons are found. Therefore, the behavioral differences between the two PN-1 overexpressing lines most likely reflect an increased cortical contribution to these deficits in TG27 mice. Two lines of GAP-43 transgenic mice under the control of the same Thy 1.2 promoter did not develop a beam balance deficit (data not shown). Thus, because in addition only hemizygous mice and littermates were used, the phenotype is probably not caused by this expression cassette but by the intrinsic properties of PN-1. Obviously it will be of great interest to explore the consequences of this highly localized expression of PN-1 protein in TG27 mice, namely on the activity of PN-1 target serine proteases (e.g., plasminogen activators or thrombin-like proteases), and their effect on the cellular and synaptic environment.

It is indicative that the serpin is endogenous in both layer $\mathrm{V}$ pyramidal and spinal motor neurons, namely in cells making long projections. It has also been found at the neuromuscular junction (Festoff et al., 1991). Overexpression may therefore enhance the vulnerability of these cells and cause axonopathy, possibly triggered by changes at the level of some synapses. Both the upregulation of $\mathrm{p} 75^{\mathrm{NTR}}$ detected at the neuromuscular junction and the changes in fast and slow muscle fibers result from synaptic modifications. Furthermore, the loss of plasticity suggested by the decrease of GAP-43 expression in cortical pyramidal neurons could also be a consequence of synaptic dysfunction. The following arguments support such a hypothesis. First, an imbalance in extracellular proteolytic activity may have an effect on (1) synaptic plasticity, as studies on the overexpression of PN-1 (Lüthi et al., 1997) and tissue plasminogen activator, a potential target protease of PN-1 (Madani et al., 1999), have shown, (2) synapse maintenance as suggested by the effect of PN-1 on in vitro synapse elimination (Liu et al., 1994), and (3) the modulation of NMDA receptor activity by proteins capable of being influenced by PN-1: for example, the thrombin receptor, PAR-1 (Gingrich et al., 2000), or tissue plasminogen activator (Nicole et al., 2001). Second, an increase in the amount of protease/inhibitor complexes because of PN-1 overexpression could modify the level or function, or both, of the low-density lipoprotein receptor-related protein (LRP) that, among other functions (for review, see Willnow et al., 1999), is responsible for uptake of protease/PN-1 complexes (Knauer et al., 1997). LRP is expressed by many CNS neurons, including cortical layer $\mathrm{V}$ cells and spinal motor neurons (Ishiguro et al., 1995). In fact, LRP signaling has been implicated in long-term potentiation (LTP) (Zhuo et al., 2000). This would also explain the changes in LTP detected in mice overexpressing or lacking PN-1 (Lüthi et al., 1997). Thus, excess PN-1 could act with time at different molecular levels to induce synaptic alterations that would consequently lead to axonopathy. It is not yet possible, however, to exclude the possibility that overexpression of the recombinant serpin affects normal protein processing, clearance, or secretion, even in the absence of detectable protein aggregates. Future work will try to distinguish between these hypotheses, using mice with more narrowly targeted overexpression in long projecting neurons.

\section{PN-1 overexpressing mice: a useful animal model}

The findings presented here validate the use of transgenic mice with neuronal PN-1 overexpression to investigate intracortical 
information transfer between the sensory and motor cortex and to study a number of cellular events (microgliosis, astrogliosis, and chronic muscle denervation/reinnervation) involved in neurodegenerative processes. Furthermore, the course of the pathology affecting both cortical and spinal motor neurons is predictable and reproducible. It does not require external intervention and recapitulates some of the initial and early histological changes found in human disease. Because these phenotypic changes occur in the absence of cell death and are not the result of overexpression of cytoskeletal proteins, these mice provide a unique model for understanding the early stages in some types of motor neuron disease and for evaluating possible treatments.

\section{REFERENCES}

Anderson JR (1985) Atlas of skeletal muscle pathology. Lancaster, UK: MTP

Baker JB, Low DA, Simmer RL, Cunningham DD (1980) Proteasenexin: a cellular component that links thrombin and plasminogen activator and mediates their binding to cells. Cell 21:37-45.

Barnéoud P, Lolivier J, Sanger DJ, Scatton B, Moser P (1997) Quantitative motor assessment in FALS mice: a longitudinal study. NeuroReport 8:2861-2865.

Campbell MJ, Morrison JH (1989) Monoclonal antibody to neurofilament protein (SMI-32) labels a subpopulation of pyramidal neurons in the human and monkey neocortex. J Comp Neurol 282:191-205.

Caroni P (1997) Overexpression of growth-associated proteins in the neurons of adult transgenic mice. J Neurosci Methods 71:3-9.

Chou SM, Taniguchi A, Wang HS, Festoff BW (1998) Serpin-serine protease-like complexes within neurofilament conglomerates of motoneurons in amyotrophic lateral sclerosis. J Neurol Sci 160[Suppl 1]:S73-S79.

Clark BH, Burright EN, Yunis WS, Larson S, Wilcox C, Hartman B, Matilla A, Zoghbi HY, Orr HT (1997) Purkinje cell expression of a mutant allele of SCA1 in transgenic mice leads to disparate effects on motor behaviors, followed by a progressive cerebellar dysfunction and histological alterations. J Neurosci 17:7385-7395.

Côté F, Collard JF, Julien JP (1993) Progressive neuronopathy in transgenic mice expressing the human neurofilament heavy gene: a mouse model of amyotrophic lateral sclerosis. Cell 73:35-46.

Donovan FM, Pike CJ, Cotman CW, Cunningham DD (1997) Thrombin induces apoptosis in cultured neurons and astrocytes via a pathway requiring tyrosine kinase and RhoA activities. J Neurosci 17:5316-5326.

Feng G, Mellor RH, Bernstein M, Keller-Peck C, Nguyen QT, Wallace M, Nerbonne JM, Lichtman JW, Sanes JR (2000) Imaging neuronal subsets in transgenic mice expressing multiple spectral variants of GFP. Neuron 28:41-51.

Festoff BW, Rao JS, Hantai D (1991) Plasminogen activators and inhibitors in the neuromuscular system: III. The serpin protease nexin I is synthesized by muscle and localized at neuromuscular synapses. J Cell Physiol 147:76-86.

Filipe MI, Lake BD (1990) Histochemistry in pathology. New York: Churchill Livingstone.

Gingrich MB, Junge CE, Lyuboslavaky P, Traynelis SF (2000) Potentiation of NMDA receptor function by the serine protease thrombin. J Neurosci 20:4582-4595.

Golde TE, Estus S, Younkin LH, Selkoe DJ, Younkin SG (1992) Processing of the amyloid protein precursor to potentially amyloidogenic derivatives. Science 255:728-730.

Hedeker D, Gibbons BW (1996) MIXOR: a computer program for mixed-effects ordinal regression analysis. Comput Methods Prog Biomed 49:157-176.

Houenou LJ, Turner PL, Li L, Oppenheim RW, Festoff BW (1995) A serine protease inhibitor, protease nexin I, rescues motoneurons from naturally occurring and axotomy-induced cell death. Proc Natl Acad Sci USA 92:895-899.

Hruska RE, Kennedy S, Silbergeld EK (1979) Quantitative aspects of normal locomotion in rats. Life Sci 25:171-179.

Ishiguro M, Imai Y, Kohsaka S (1995) Expression and distribution of low density lipoprotein receptor-related protein mRNA in the rat central nervous system. Brain Res Mol Brain Res 33:37-46.

Jacobs KM, Neve RL, Donoghue JP (1993) Neocortex and hippocampus contain distinct distributions of calcium-calmodulin protein kinase II and GAP43 mRNA. J Comp Neurol 336:151-160.

Jacobson RD, Virag I, Skene JH (1986) A protein associated with axon growth, GAP-43, is widely distributed and developmentally regulated in rat CNS. J Neurosci 6:1843-1855.

Knauer DJ, Majumdar D, Fong PC, Knauer MF (2000) SERPIN regulation of factor XIa. The novel observation that protease nexin-1 in the presence of heparin is a more potent inhibitor of factor XIa than C1 inhibitor. J Biol Chem 275:37340-37346.

Knauer MF, Hawley SB, Knauer DJ (1997) Identification of a binding site in protease nexin I (PN1) required for the receptor mediated internalization of PN1-thrombin complexes. $\mathrm{J}$ Biol Chem 272:12261-12264.

Leifer D, Kowall NW (1993) Immunohistochemical patterns of selective cellular vulnerability in human cerebral ischemia. J Neurol Sci 119:217-228.

Liu Y, Fields RD, Festoff BW, Nelson PG (1994) Proteolytic action of thrombin is required for electrical activity-dependent synapse reduction. Proc Natl Acad Sci USA 91:10300-10304.

Love FM, Thompson WJ (1998) Schwann cells proliferate at rat neuromuscular junctions during development and regeneration. J Neurosci 18:9376-9385.

Lüthi A, van der Putten H, Botteri FM, Mansuy IM, Meins M, Frey U, Sansig G, Portet C, Schmutz M, Schroder M, Nitsch C, Laurent JP Monard D (1997) Endogenous serine protease inhibitor modulates epileptic activity and hippocampal long-term potentiation. J Neurosci 17:4688-4699.

Madani R, Hulo S, Toni N, Madani H, Steimer T, Muller D, Vassalli JD (1999) Enhanced hippocampal long-term potentiation and learning by increased neuronal expression of tissue-type plasminogen activator in transgenic mice. EMBO J 18:3007-3012.

Manetto V, Sternberger NH, Perry G, Sternberger LA, Gambetti P (1988) Phosphorylation of neurofilaments is altered in amyotrophic lateral sclerosis. J Neuropathol Exp Neurol 47:642-653.

Mansuy IM, van der Putten H, Schmid P, Meins M, Botteri FM, Monard D (1993) Variable and multiple expression of protease nexin-1 during mouse organogenesis and nervous system development. Development 119:1119-1134.

Monard D (1993) Tinkering with certain blood components can engender distinct functions in the nervous system. Perspect Dev Neurobiol 1:165-168.

Monard D, Suidan HS, Nitsch C (1992) Relevance of the balance between glia-derived nexin and thrombin following lesion in the nervous system. Ann NY Acad Sci 674:237-242.

Monnet-Tschudi F, Zurich MG, Pithon E, van Melle G, Honegger P (1995) Microglial responsiveness as a sensitive marker for trimethyltin (TMT) neurotoxicity. Brain Res 690:8-14.

Niclou SP, Suidan HS, Pavlik A, Vejsada R, Monard D (1998) Changes in the expression of protease-activated receptor 1 and protease nexin-1 mRNA during rat nervous system development and after nerve lesion. Eur J Neurosci 10:1590-1607.

Nicole O, Docagne F, Ali C, Margaill I, Carmeliet P, MacKenzie ET, Vivien D, Buisson A (2001) The proteolytic activity of tissueplasminogen activator enhances NMDA receptor-mediated signaling. Nat Med 2:59-64.

Oppenheim RW, Cole T, Prevette D (1989) Early regional variations in motoneuron numbers arise by differential proliferation in the chick embryo spinal cord. Dev Biol 133:468-474

Pestronk A, Drachman DB (1978) A new stain for quantitative measurement of sprouting at neuromuscular junctions. Muscle Nerve 1:70-74

Reinhard E, Suidan HS, Pavlik A, Monard D (1994) Glia-derived nexin/ protease nexin- 1 is expressed in a subset of neurons in the rat brain. J Neurosci Res 37:256-270.

Roberson MD, Toews AD, Bouldin TW, Weaver J, Goines ND, Morell $P$ (1995) NGFR-mRNA expression in sciatic nerve: a sensitive indicator of early stages of axonopathy. Brain Res Mol Brain Res 28:231-238.

Scotti AL, Monard D, Nitsch C (1994) Re-expression of glia-derived nexin/protease nexin 1 depends on mode of lesion-induction or terminal degeneration: observations after excitotoxin or 6-hydroxydopamine lesions of rat substantia nigra. J Neurosci Res 37:155-168.

Sisodia SS, Koo EH, Beyreuther K, Unterbeck A, Price DL (1990) Evidence that beta-amyloid protein in Alzheimer's disease is not derived by normal processing. Science 248:492-495.

Smith-Swintosky VL, Zimmer S, Fenton IIJW, Mattson MP (1995) Protease nexin-1 and thrombin modulate neuronal $\mathrm{Ca}^{2+}$ homeostasis and sensitivity to glucose deprivation-induced injury. $\mathrm{J}$ Neurosci $15: 5840-5850$.

Sommer J, Gloor SM, Rovelli GF, Hofsteenge J, Nick H, Meier R, Monard D (1987) cDNA sequence coding for a rat glia-derived nexin and its homology to members of the serpin superfamily. Biochemistry 26:6407-6410.

Spittaels K, Van den Haute C, Van Dorpe J, Bruynseels K, Vandezande K, Laenen I, Geerts H, Mercken M, Sciot R, Van Lommel A, Loos R Van Leuven F (1999) Prominent axonopathy in the brain and spinal cord of transgenic mice overexpressing four-repeat human tau protein. Am J Pathol 155:2153-2165.

Stanfield BB, O'Leary DDM, Fricks C (1982) Selective collateral elimination in early postnatal development restricts cortical distribution of rat pyramidal tract neurones. Science 298:371-373.

Streit WJ, Kreutzberg GW (1987) Lectin binding by resting and reactive microglia. J Neurocytol 16:249-260.

Suidan HS, Stone SR, Hemmings BA, Monard D (1992) Thrombin 
causes neurite retraction in neuronal cells through activation of cell surface receptors. Neuron 8:363-375.

Taniuchi M, Clark HB, Johnson EMJ (1986) Induction of nerve growth factor receptor in Schwann cells after axotomy. Proc Natl Acad Sci USA 83:4094-4098.

Thor S, Ericson J, Brännström T, Edlund T (1991) The homeodomain LIM protein Isl-1 is expressed in subsets of neurons and endocrine cells in the adult rat. Neuron 7:881-889.

Troncoso E, Muller D, Czellar S, Zoltan KJ (2000) Epicranial sensory evoked potential recordings for repeated assessment of cortical functions in mice. J Neurosci Methods 97:51-58.

Troost D, Sillevis Smitt PA, de Jong JM, Swaab DF (1992) Neurofilament and glial alterations in the cerebral cortex in amyotrophic lateral sclerosis. Acta Neuropathol (Berl) 84:664-673.

Tsang YM, Chiong F, Kuznetsov D, Kasarskis E, Geula C (2000) Motor neurons are rich in non-phosphorylated neurofilaments: cross-species comparison and alterations in ALS. Brain Res 861:45-58.

Tseng GF, Prince DA (1996) Structural and functional alterations in rat corticospinal neurons after axotomy. J Neurophysiol 75:248-267.

van der Putten H, Wiederhold KH, Probst A, Barbieri S, Mistl C, Danner S, Kauffmann S, Hofele K, Spooren WP, Ruegg MA, Lin S, Caroni P,
Sommer B, Tolnay M, Bilbe G (2000) Neuropathology in mice expressing human $\alpha$-synuclein. J Neurosci 20:6021-6029.

Vaughan PJ, Su J, Cotman CW, Cunningham DD (1994) Protease nexin-1, a potent thrombin inhibitor, is reduced around cerebral blood vessels in Alzheimer's disease. Brain Res 668:160-170.

Vaughan PJ, Pike CJ, Cotman CW, Cunningham DD (1995) Thrombin receptor activation protects neurons and astrocytes from cell death produced by environmental insults. J Neurosci 15:5389-5401.

Wagner SL, Geddes JW, Cotman CW, Lau AL, Gurwitz D, Isackson PJ Cunningham DD (1989) Protease nexin-1, an antithrombin with neurite outgrowth activity, is reduced in Alzheimer disease. Proc Nat Acad Sci USA 86:8284-8288.

Werb Z (1997) ECM and cell surface proteolysis: regulating cellular ecology. Cell 91:439-442.

Willnow TE, Nykjaer A, Herz J (1999) Lipoprotein receptors: new roles for ancient proteins. Nat Cell Biol 1:E157-E162.

Xu Z, Cork LC, Griffin JW, Cleveland DW (1993) Increased expression of neurofilament subunit NF-L produces morphological alterations that resemble the pathology of human motor neuron disease. Cell 73:23-33.

Zhuo M, Holtzman DM, Li Y, Osaka H, DeMaro J, Jacquin M, Bu G (2000) Role of tissue plasminogen activator receptor LRP in hippocampal long-term potentiation. J Neurosci 20:542-549. 